\title{
Read the book and see the film? The Consumption of Different Versions of Cultural Goods
}

\author{
A. Collins ${ }^{\mathrm{a}}$, A. E. Scorcu ${ }^{\mathrm{b} *}$ and R. Zanola ${ }^{\mathrm{c}}$
}

\begin{abstract}
Using a sample of individuals that consumed both the book and movie versions of some cultural experience goods, we investigate the precedence and the preference for a particular version. The likelihood of consuming a version increases as information about that version increases. The preference and the precedence in consumption are related to genre, age and reading habits.
\end{abstract}

Key words: experience goods, repeated consumption, cultural goods

JEL classification: D11, D12, Z11

\section{Introduction}

The consumption of different versions of an experience good has been extensively analysed. The consumer, initially uncertain about the relevant characteristics of the good, can assess its overall quality only after the consumption (Nelson, 1970). The release of different versions on one hand can keep high the interest of the consumer in the good but also makes the learning about its overall quality more difficult.

Particular attention has been directed to the case of the version release strategies of a firm, especially with reference to the technological features, e.g. the cases under which the free provision of the basic (low quality) version of some software can induce the future purchase at a positive price for the advanced (high quality) version, or influence the appropriate timing of release for the "new" version of an experience good (the DVD release of a movie, after the theatrical release).

In this paper we focus upon the consumption of different versions (book and movie) of the same cultural experience good by the same consumer ${ }^{1}$.

Whereas for some individuals the enjoyment from the book version might be spoilt were they to watch the movie version (and vice versa) for others the reading the book version could inspire the watching of the movie (and vice versa). The success of the "first" version is an observable proxy for the high quality of the underlying cultural content and signals, in an information leveraging

${ }^{\text {a }}$ Economics and Finance Group, University of Portsmouth Business School, Portland Street, Portsmouth P01 $3 D E$, England

${ }^{\mathrm{b}}$ Department of Economics, University of Bologna, Strada Maggiore 45, I-40125 Bologna, Italy

* Corresponding author. E-mail: antonello.scorcu@ unibo.it

${ }^{\mathrm{c}}$ Department of Public Policy and Public Choice, University of Eastern Piedmont, Corso Borsalino 83, 15100

Alessandria, Italy 
framework (Choi, 2003), the likely high quality of the second version, thereby increasing its expected sales.

At the same time, among those that read the book and watched the movie, some (the book lovers) will prefer the book versions, while others (the movie lovers) will prefer the movie or declare equal appreciation of the two versions.

Several studies have explored the characteristics of the cultural dimensions of the households and the consumption of different cultural goods ${ }^{2}$. Central to our analysis, however, is the existence of some households that consume sequentially both versions of the same cultural content. We empirically investigate the consumers' evaluation process of the two versions of the good, taking into account the existence of a sequence in the consumption process, and identifying the different characteristics and motivations of these groups.

\section{Data description and model specification}

Our data derive from field research conducted in February 2009 in a large department store in Ravenna (Italy). We interview customers of different ages and working status, on different days of the week and at different hours of the day. We collected some information about the socioeconomic status, genre and age; no information about income is available. Whereas most individuals declared an interest in movies or in books, we consider only those who consumed both versions of the same cultural content. There is no closed list of book-movie pairs.

Even if most individuals report only one case of consumption of a book-movie pair, for some this type of consumption is habitual. The sample consists of 72 individuals, generating a total of 169 observations, as each respondent consumes, on average, 2.35 movie-book pairs.

Whereas the empirical evidence drawn from this sample cannot constitute a basis for any generalization, to the best of our knowledge, no other data exists on such a topic; hence this case study can be of some utility in developing modes of analysis of the pattern of consumption in complementary experienced goods.

Table 1 shows some descriptive statistics of the dataset. In most of the cases the book version has been consumed first, and is also the most appreciated version. The respondents are often females, strong readers and have consumed the first (book) version for curiosity. In the case of the movie version (typically the second version consumed) the main driver is the previous consumption of the

\footnotetext{
${ }^{1}$ A different case is the repeated consumption of an identical cultural good e.g. Collins et al (2008).

2 Prieto-Rodríguez and Fernández-Blanco (2000) showed that the likelihood of listening to classical music is positively related to the listening to popular music. Favaro and Frateschi (2007) analyzed the characteristics of classical music lovers, popular music lovers and "omnivores".
} 
other version. The information from TV or newspaper as well the advice of friends and relatives are important (especially in the movie case) but never constitutes the main motivation of consumption.

Table 1. Descriptive statistics

\section{1.a - Individual characteristics (\%)}

\begin{tabular}{lcccc}
\hline & $\begin{array}{c}\text { First read book } \\
\text { group }\end{array}$ & $\begin{array}{c}\text { Book lovers } \\
\text { group }\end{array}$ & $\begin{array}{c}\text { Movie lovers } \\
\text { group }\end{array}$ & $\begin{array}{c}\text { Equal appreciators } \\
\text { group }\end{array}$ \\
\hline Whole sample & 0.75 & 0.75 & 0.12 & 0.12 \\
Female & 0.73 & 0.73 & 0.14 & 0.13 \\
Male & 0.91 & 0.87 & 0.04 & 0.09 \\
Age 18-25 & 0.51 & 0.82 & 0.16 & 0.02 \\
Age 26-35 & 0.71 & 0.67 & 0.25 & 0.08 \\
Age 36-50 & 0.86 & 0.89 & 0.09 & 0.02 \\
Age 50-60 & 0.87 & 0.55 & 0.05 & 0.39 \\
Age 60+ & 1.00 & 0.5 & 0.00 & 0.5 \\
Read 0-5 books & 0.80 & 0.75 & 0.23 & 0.03 \\
Read 5-12 books & 0.72 & 0.91 & 0.06 & 0.02 \\
Read 12+ books & 0.74 & 0.66 & 0.11 & 0.23 \\
\hline
\end{tabular}

\section{1-b - Dummy variables}

\begin{tabular}{|c|c|c|c|}
\hline Variable & Mean [Std. Dev.] & Variable & Mean [Std. Dev.] \\
\hline \multicolumn{2}{|l|}{ Age } & \multicolumn{2}{|l|}{ Consumption sequence } \\
\hline Age $18-25$ & $0.266[0.443]$ & First book & $0.738[0.440]$ \\
\hline Age $26-35$ & $0.142[0.350]$ & First movie & $0.262[0.441]$ \\
\hline Age $36-50$ & $0.337[0.474]$ & \multirow{2}{*}{\multicolumn{2}{|c|}{ Genre }} \\
\hline Age $50-60$ & $0.225[0.419]$ & & \\
\hline Age $60+$ & $0.024[0.152]$ & Female & $0.849[0.385]$ \\
\hline \multicolumn{2}{|c|}{ Book reading in a year } & \multicolumn{2}{|c|}{ Consumption preference } \\
\hline $0-5$ books & $0.232[0.423]$ & Book lovers & $0.738[0.441]$ \\
\hline $5-12$ books & $0.291[0.455]$ & Movie lovers & $0.122[0.328]$ \\
\hline $12+$ books & $0.480[0.501]$ & Equal appreciators & $0.140[0.348]$ \\
\hline \multirow{2}{*}{\multicolumn{2}{|c|}{$\begin{array}{l}\text { Reasons for the consumption of the book version } \\
\text { medion }\end{array}$}} & \multirow{2}{*}{\multicolumn{2}{|c|}{$\begin{array}{l}\text { Reasons for the consumption of the movie version } \\
\text { media_coverage }\end{array}$}} \\
\hline & & & \\
\hline $\begin{array}{l}\text { (info from TV, newspapers,..) } \\
\text { friends_advice }\end{array}$ & $0.157[0.364]$ & $\begin{array}{l}\text { (info from TV, newspapers,..) } \\
\text { friends_advice }\end{array}$ & $0.052[0.223]$ \\
\hline (info from friends, relatives) & $0.232[0.424]$ & (info from friends, relatives) & $0.163[0.370]$ \\
\hline gift & $0.041[0.198]$ & gift & - \\
\hline pure_curiosity & $0.459[0.500]$ & pure_curiosity & $0.058[0.235]$ \\
\hline $\begin{array}{l}\text { inspired_by_movie } \\
\text { compare_movie }\end{array}$ & $0.157[0.364]$ & $\begin{array}{l}\text { inspired_by_book } \\
\text { compare book }\end{array}$ & $0.459[0.500]$ \\
\hline (comparison after movie version) & $0.006[0.076]$ & (comparison after book version) & $0.221[0.416]$ \\
\hline \multicolumn{2}{|c|}{ Type of movie consumption } & \multicolumn{2}{|l|}{ Genre of movie } \\
\hline Movie watched on TV & $0.076[0.265]$ & Comedy & $0.087[0.283]$ \\
\hline Movie viewed at cinema & $0.628[0.485]$ & Thriller & $0.203[0.404]$ \\
\hline Movie watched on DVD & $0.262[0.441]$ & Fantasy & $0.500[0.501]$ \\
\hline Movie downloaded & $0.052[0.223]$ & Romance & $0.209[0.408]$ \\
\hline
\end{tabular}

The binary value of the dependent variables (reading the book version first $=1$, otherwise $=0$; better the book than the movie $=1$, otherwise $=0$, etc.) suggests the estimation of a series of probit regressions. The dependent variable $y_{i}^{*}$, is linearly related to a series of observables variables, $x_{i}$, $i=1, \ldots, \mathrm{I}$, and to other unobserved factors captured through the error term, $\varepsilon_{i}$ :

$$
y_{i}^{*}=\alpha x_{i}+\varepsilon_{i}
$$


$y_{i}^{*}$ is proxied by the actual choice, $y_{i}$, equal to one when the individual declares such a choice and zero otherwise. The probability that $y_{i}=1$ is therefore:

$$
P\left(y_{i}=1 \mid x_{i}\right)=\Phi\left(x_{i}^{\prime} \beta\right)
$$

where $\Phi$ is the cumulative density function for the standard normal and $\beta$ is the vector of coefficients to be estimated.

We use a general to specific modelling strategy. Starting from a rather general (and possibly overparameterised) model, we discard non-significant covariates. The pseudo- $\mathrm{R}^{2}$ is used as the insample criterion in choosing the final specification. Whereas no individual fixed effects are considered, as this would restrict the sample to an exceedingly low number of cases of individuals with multiple consumption of different book-movie bundles, the standard errors are grouped by individuals.

\section{Empirical Evidence}

The consumption timing in the case under scrutiny is usually sequenced from the book to the movie; opposite cases are much less frequent. In each consumption precedence regression we consider only the information channels relevant to the version consumed at first. Table 2 shows the estimated values of the coefficients, the corresponding P-values and some diagnostics tests the preferred specification of the probit regression, using the Book First or the Movie First as dependent variables ${ }^{3}$.

The probability of reading the book before watching the movie version increases with age but is not significantly affected by the gender of the consumer. The influence of media and critics, as well the existence of a word of mouth effect, driven by friends and relatives, about the book version of the cultural good, positively affects the likelihood of reading the book first. The same mechanism emerges in the movie case. Being a male, having reading habits of average strength and being at least in the forties impacts negatively on the probability of watching at the movie first. Hence, under the assumption that the provision of information is exogenous, more information on a specific version increases the likelihood of consumption for the cultural good.

In Table 3 we show the probit regressions for the book lovers, movie lovers and equal appreciators cases.

\footnotetext{
${ }^{3}$ In particular, the area under the ROC curve summarizes the overall discriminatory and predictive power of the regression. Cf. Hosmer and Lemeshow, 2000.
} 


\section{Dependent dummy variable Variables Male}

Age 18-25

Age 26-35

Read 5-12 books

$B$ media

B friends

B pure curiosity

M media

$\mathrm{M}$ friends

M pure curiosity

Thriller

Constant

N. obs

Pseudo R2

Log pseudolikelihood

Wald chi2(13)

Pearson goodeness of fit

Area under ROC curve
Table 2 - Consumption Precedence

Book version consumed first

Coeff. [P value]

$-.908[0.011]$

$-.867[0.104]$

$1.837[0.001]$

$1.268[0.002]$

$1.198[0.007]$
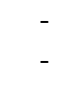

$1.001[0.052]$

$-0.058[0.869]$

$$
\begin{gathered}
169 \\
0.2924 \\
-67.052 \\
20.13[0.003] \\
\operatorname{chi} 2(19)=24.12[0.192] \\
0.854
\end{gathered}
$$

Movie version consumed first Coeff. [P value]

$-2.373[0.036]$

0.814 [0.028]

$1.360[0.019]$

$-1.079[0.033]$

$2.242[0.000]$

$3.087[0.000]$

$2.945[0.000]$

$-4.255[0.000]$

$$
\begin{gathered}
169 \\
0.577 \\
-40.066 \\
62.04[0.000] \\
\operatorname{chi} 2(17)=23.53[0.133] \\
0.950
\end{gathered}
$$

Note: Std. Err. adjusted for 69 individual clusters

$\begin{array}{lc}\begin{array}{l}\text { Dependent } \\ \text { dummy variable: }\end{array} & \text { Book Lovers } \\ \text { Variables } & \text { Coeff. [P value] } \\ \text { Male } & 0.679[0.141] \\ \text { Age 18-25 } & \\ \text { Age 26-35 } & \\ \text { Age 36-50 } & 0.868[0.019] \\ \text { Age 50-60 } & \\ \text { Age 60+ } & -1.907[0.011] \\ \text { Read 0-5 books } & \\ \text { Read 5-12 books } & 0.839[0.019] \\ \text { First read book } & 0.746[0.022] \\ \text { B media } & 1.297[0.008] \\ \text { M friends } & 1.050[0.021] \\ \text { M media } & \\ \text { Movie downloaded } & \\ \text { Fantasy } & \\ \text { Constant } & -0.597[0.027] \\ & -0.277[0.407] \\ \text { N. obs } & \\ \text { Pseudo R2 } & 169 \\ \text { Log pseudolikel. } & 0.263 \\ \text { Wald test } & -69.799 \\ \text { Pearson goodeness } & \text { chi2 }(8)=38.45[0.000] \\ \text { of fit } & =37.61[0.307] \\ \text { Area under ROC } & \\ \text { Note: Std. Err. adjusted for } 69 \text { individual } & \end{array}$

Table 3 - Consumption Preference Movie lovers

Coeff. [P value] -0.898 [0.098]

$-0.828[0.066]$

1.789 [0.001]

$-2.360[0.000]$

$-1.558[0.000]$

1.255 [0.027]

$1.426[0.003]$

-0.820 [0.039]

169
0.453
-34.695
$\operatorname{chi} 2(7)=52.63[0.000]$
$\operatorname{chi} 2(23)=19.66[0.662]$
0.923

Equal Appreciators

Coeff. [P value]

-1.451 [0.027]

$-2.072[0.001]$

$-1.469[0.017]$

$-1.568[0.025]$

$1.997[0.000]$

$-1.261[0.075]$

1.739 [0.010]

-1.695 [0.000]

169
0.483
-32.804
$\operatorname{chi} 2(7)=79.70[.000]$
$\operatorname{chi} 2(28)=2.89[1.000]$
0.933

Note: Std. Err. adjusted for 69 individual clusters

Males are more likely to prefer book versions, whereas females prefer the movie version. The age effects have no clear pattern in the three regressions. Young consumers are less likely to be equal appreciators, but no significant effect emerges for the book and the movie lovers groups. Weak 
readers prefer the movie version, while average readers (people reading from 5 to 12 books within one year) tend to prefer the book version.

The book consumption precedence, i.e. the fact that the book version has been consumed before the movie version, exerts a significant positive effect on the book lovers and the equal appreciator groups, and a negative effect on the movie lovers, suggesting a sort of a priori preference for a given version. The advice of the friends about a movie exerts a positive effect for the book and a negative for the movie lover groups. Some collection items of the strong movie watchers are downloaded, and it is not surprising that the download dummy enters with a positive sign in the movie lover regression. It is often said that the movie transposition of some books is difficult, and is at the risk of reducing the quality of the cultural content. However, for the fantasy genre, movies are more appreciated than books, perhaps because a young consumer (the typical consumer of such a genre) is more attuned with the visual rather than with the written content.

\section{Concluding remarks}

In this note we have explored the consumption preferences for two potentially complementary versions of the same cultural content. This note makes two contributions. The empirical analysis of people sequentially consuming both book and movie versions of the same cultural item adds to the economic literature on experience goods and contributes to assess marketing decisions. Consistent with previous studies on cultural consumption, we find evidence of the word-of-month effect. Specifically, the empirical evidence suggests the existence of a positive effect of the friends and relatives as well of critics and media in stimulating the consumption of both books and movies.

The second contribution concerns the consumers' preferences between different versions of the same cultural good. Departing from the existing literature, in our framework, males tend to prefer the book version, whereas females seem to appreciate more the movie version. While we cannot rule out alternative explanations, two explanations are consistent with such a result. Although women are book lovers, the opportunity cost of leisure time is expected to be higher for men who may prefer to allocate it in shorter daily consumption periods (such as the case for books) than in one continuous longer time period which is required to watch a movie. Moreover, the books that become movies are a small sample of book production. Most of them are thrillers, fantasy, etc.- arguably a particular category which are likely to be more appreciate by men.

Additionally, the movie version is expected to be a competitor with the book version of the same item and it can be considered a substitute form of consumption. As book consumption decreases, one would expect a growth in movie attendance. Our results confirm such an expectation, as a weak book reader tends to favor the movie version, whereas an average reader tends to prefer the book version. 
Whereas this study offers a preliminary explanation of the unexplored repeated consumption of different versions of cultural experience goods, the evidence provided in this research is limited to Italy. An international comparative study is necessary to evaluate the empirical coverage of our results. Moreover, the size of the dataset used might make our conclusions less robust and thus ideally a more extensive dataset should be used in subsequent work to control for bias arising from measurement errors.

\section{References}

Choi, J. P. (2003) Bundling new products with old to signal quality, with application to the sequencing of new products. International Journal of Industrial Organization, 21, 1179-1200.

Collins, A., Hand, C. and Linnell, M. (2008) Analyzing repeat consumption of identical cultural goods: some exploratory evidence from moviegoing, Journal of Cultural Economics, 32(3), 187-99.

Favaro D. and Frateschi C. (2007) A discrete choice model of consumption of cultural goods: the case of music, Journal of Cultural Economics, vol. 31(3), 205-234.

Hosmer, D. and Lemeshow, S. (2000) Applied Logistic Regression, Wiley \& Sons, New York.

Nelson, P. (1970), Information and Consumer Behavior, Journal of Political Economy. 78, 311-329.

Prieto-Rodríguez J. and Fernández-Blanco V. (2000) Are Popular and Classical Music Listeners the Same People?, Journal of Cultural Economics, 24, 147-164 